\title{
Rompendo a superfície das formas para adentrar em seu conteúdo: uma proposta pedagógica da Secretaria Municipal de Educação de Curitiba para um ensino religioso voltado para a diversidade
}

\author{
Taciane Jaluska
}

\section{RESUMO}

Atualmente há muita discussão acadêmica a respeito da criação de novos recursos e estratégias para inserir o componente curricular Ensino Religioso em um modelo de educação transformadora. Nesse sentido, a presente pesquisa tem como objetivo apresentar, por meio de uma pesquisa qualitativa-descritiva, as novas propostas pedagógicas da Secretaria Municipal de Curitiba visando uma política para um ensino religioso voltado para a diversidade utilizando-se da arte e dos espaços sagrados para a geração de conhecimento próprio. Os resultados da pesquisa apontam que as visitas permitem não apenas conhecer outras realidades, mas perceber e valorizar a diversidade cultural brasileira, pois a cidadania só se constrói com o reconhecimento e respeito pelas muitas formas de se viver e de se pensar o mundo.

Palavras-chave: Ensino religioso; Arte sacra; Espaço sagrado; Propostas pedagógicas

BREAKING THE SURFACE OF THE FORMS TO PENETRATE ITS CONTENT: A PEDAGOGICAL PROPOSAL OF THE MUNICIPAL SECRETARY OF EDUCATION OF CURITIBA FOR A RELIGIOUS EDUCATION FOCUSED ON DIVERSITY

\begin{abstract}
Currently there is much academic discussion about the creation of new resources and strategies to insert the component Religious Education curriculum in a model of transformative education. In this sense, the present research aims to present, through a qualitative-descriptive research, the new pedagogical proposals of the Municipal Secretariat of
\end{abstract}


Curitiba aiming at a policy for a religious teaching focused on diversity using art and sacred spaces for the generation of own knowledge. The results of the research show that the visits allow not only to know other realities, but to understand and value Brazilian cultural diversity, since citizenship is only built with the recognition and respect for the many ways of living and thinking the world.

Keywords: Religious education; Religious art; Sacred space; Pedagogical proposals

\section{Introdução}

A Lei das diretrizes e bases da educação nacional, Lei 9.394/96, destaca em seu primeiro artigo que a educação pode se desenvolver "na vida familiar, na convivência humana, no trabalho, nas instituições de ensino e pesquisa, nos movimentos sociais e organizações da sociedade civil e nas manifestações culturais" (BRASIL, 1996). Nesse sentido, com a preocupação atual a respeito da qualidade da educação na formação do sujeito é preciso considerar a diversidade de espaços como importantes instrumentos educativos.

A arte desenvolveu-se, ao longo dos tempos, servindo às religiões, como verdadeiro instrumento auxiliar aos cultos, por meio de esculturas, pinturas, arquitetura de maneira que é impossível dissociar o desenvolvimento da história da arte das práticas religiosas. A arte religiosa é, sobretudo, utilitária. Sempre apresenta finalidades específicas de acordo com o contexto em que é realizada. Trata-se de uma evocação do sagrado por meio da materialidade, ou seja, por meio da beleza visível busca-se chegar ao mistério invisível.

Para o teólogo Paul Tillich (apud CALVANI, 2010, p.74-75) as representações artísticas o tornaram consciente de que o ser humano é capaz de romper a superfície das formas e penetrar em seu conteúdo, no poder espiritual que pulsa através delas, pois elas representam o fundamento divino do ser e tudo que representa esse poder pode ser considerado indiretamente religioso. Tillich afirma também que há três modos de experimentar e expressar a realidade última: o modo direto, por meio da religião, e os modos indiretos, por meio da filosofia e das artes. 
A arte torna-se uma espécie de revelação muda que fala mais perceptivelmente a mente interpretativa que apenas palavras e conceitos, fortalecendo o conhecimento do indivíduo que experimenta sensorialmente a obra. "Da mesma forma como olhamos as coisas, assim as coisas olham para nós com a expectativa de serem recebidas e com a oferta de nos enriquecer na união cognitiva." (TILLICH, 1967, p.88). Essa experiência estética, que transcende a racionalidade por meio da intuição, torna a arte um instrumento capaz de gerar conhecimentos próprios, ultrapassando o modo exclusivamente cognitivo, pertencente às outras ciências.

Nesse sentido, a presente pesquisa tem como objetivo apresentar, por meio de uma pesquisa qialitativa-descritiva, as novas propostas pedagógicas praticadas na Secretaria Municipal de Curitiba visando uma política para um ensino religioso mais inclusivo, democrático e plural, ou seja, voltado para a diversidade das religiões brasileiras. Para isso, em um primeiro momento teórico apresenta-se a fundamentação teórica a respeito da arte e suas potencialidades como geradora de conhecimentos próprios e a importância do uso dos diferentes espaços sagrados da cidade para o ensino religioso, bem como um breve histórico do Ensino Religioso como componente curricular no Brasil. Em um segundo momento, são apresentados as diferentes ações da Secretaria Municipal de Educação de Curitiba para aplicar essas novas políticas pedagógicas.

\section{A arte sacra no espaço sagrado e suas potencialidades na geração do conhecimento}

A iconografia vem do grego e significa escrever, comunicar-se, por meio de imagens. O ser humano necessita da materialidade das coisas para poder sentir-se e expressar-se, de forma especial, em sua religiosidade. "No ícone, como em geral na cultura eclesial, se constrói aquilo que não está dado para a experiência sensível, e da qual, por isso, mesmo que seja de um modo esquemático, necessitamos proporcionar uma experiência visível”. (SÁEZ, 2009, p. 53). Por isso, as representações artísticas das realidades transcendentes encontraram espaço na arte sacra dos lugares sagrados para servir de mediação do Mistério. "O ícone 
e o nome são, pois, os símbolos antinômicos da síntese espiritual, as portas de acesso a perspectiva divina sobre a vida" (SÁEZ, 2009, p.50).

A arte sacra evoca o Divino por meio da materialidade, ou seja, por meio da beleza visível busca expressar o Mistério invisível, não como cópia fiel nem como fotografia, mas sim como representação simbólica. "O símbolo é uma realidade que carrega em si a energia de outra realidade, uma realidade interior que nunca está revelada em si mesma" (FLORENSKIJ, 1995, p. 252 apud SÁEZ, 2009, p.46).

A arte torna-se essencial na medida em que fornece a teologia, de maneira privilegiada, a compreensão que o ser humano tem de si mesmo, do mundo material e espiritual. O teólogo Calvani (2010, p.7475) em uma profunda análise sobre as artes nas obras de Paul Tillich destaca o interesse do teólogo em compreender o uso das imagens no Cristianismo. Para Tillich, além da religião, que é o modo direto de experimentar e conhecer a realidade última há também dois modos indiretos que podem levar ao conhecimento de Deus: a filosofia e as artes. Calvani (2010. p.79) afirma que "dizer que a experiência estética é de índole revelatória, significa afirmar que a arte indica a situação espiritual de uma época, de um modo completamente distinto das outras formas de conhecimento humano". Do mesmo modo que Florenskij, quando menciona que a arte, enquanto símbolo não é somente expressão da realidade mais alta que se faz transparente, mas também o reflexo do estado espiritual de uma época determinada" (FLORENSKIJ, 1995, p.134 apud SÁEZ, 2009, p.46). Portanto, esse caminho não é somente meio de expressão espiritual, mas também é fonte de fé e reflexão teológica.

Assim a arte torna-se uma espécie de revelação muda que fala mais perceptivelmente a mente interpretativa que apenas palavras e conceitos, fortalecendo o conhecimento do indivíduo que experimenta sensorialmente a obra. Diferentemente do caminho da filosofia, que busca sentido por meio da razão, a arte transcende essa razão pela intuição, não que ela abandone a racionalidade, mas seu primeiro canal de percepção é sensorial, somente depois de passar pela via sensorial é que o indivíduo submete as informações obtidas às categorias conceituais. Essa experiência estética, que transcende a racionalidade por meio da intuição, torna a arte um instrumento capaz de gerar conhecimentos próprios, ultrapassando o modo exclusivamente cognitivo, pertencente às 
outras ciências. "Cada palavra que é pronunciada provoca uma vibração interior, e o mesmo ocorre com cada objeto reproduzido em imagem. Privar-se dos meios suscetíveis de provocar essa vibração equivale a empobrecer nossos meios de expressão" (KANDINSKY, 1996, p.81).

Quem quer que aspire praticar teologia da cultura principalmente em sua aplicação estética deve inicialmente temperar seu racionalismo crítico com doses maciças de sensibilidade e intuição. Claro que isso não se produz repentinamente e algumas pessoas, talvez, de tão deformadas pelo racionalismo nunca alcançariam um grau mínimo de sensibilidade e intuição artísticas. (CALVANI, 2010, p. 78)

Os lugares sagrados não são construídos apenas para abrigar os fiéis na celebração, mas também são pensados de modo a apresentarem elementos pedagógicos e catequéticos que facilitem a funcionalidade litúrgica, aliando sua funcionalidade à tentativa de representar visualmente todo o resplendor da beleza divina por meio da arte sacra. Segundo Fernandes (2011, p.283) " [...] o momento interativo do sujeito com a obra de arte, seja ela qual for, produz emoções e interrogações, provocando o sujeito para elaborar juízos, por meio dos quais se produz e se reelabora o conhecimento". Por isso, a arte sacra torna-se espaço para a educação transformadora, pois "o ser humano pode se servir da arte sagrada para educar sua sensibilidade, estando cada vez mais aberto, em todos os sentidos, para acolher o Mistério e torná-lo presente e atuante em sua própria vida" (PASTRO; TAVARES, 2010, p.42).

Nesse sentido, os espaços sagrados caracterizam-se por serem lugares de culto e práticas religiosas, acima de tudo, lugares de manifestações do sagrado e, são, na maioria das vezes, dotados de arquitetura e arte singular, estas que, juntamente com os demais elementos inerentes à religião, conferem o formato característico que distinguem os espaços sagrados das demais construções civis que os rodeiam.

De acordo com Gil Filho (2008, p.49) o espaço sagrado que é produto da consciência religiosa concreta "se apresenta como palco privilegiado das práticas religiosas. Por ser próprio do mundo da percepção, o espaço sagrado apresenta marcas distintivas da religião, conferindo-lhe singularidades peculiares aos mundos religiosos". O que torna o espaço ‘sagrado' é o valor atribuído a ele, ou seja, os espaços sagrados não 
são apenas monumentos concretos, como podem ser também espaços da natureza, como rios, montanhas, árvores, entre outros, que, por meio de um processo de simbolização humana, ganham atributos de pura abstração. "Na sacralização do espaço, as crenças, os ritos religiosos encontram um centro de referência no qual o espírito humano pode fixar mais facilmente a identidade das coisas religiosas", espacializando o sentir religioso. (SILVA; GIL FILHO, 2009, p.80)

Os espaços sagrados, em sua maioria, buscam aliar sua funcionalidade à busca da beleza estética o que os transforma, além de lugares sagrados, patrimônios culturais da humanidade sendo que, constituídos de tradição e memória, são o solo propício para o desenvolvimento da educação do fenômeno religioso/cultural de nossa sociedade.

De acordo com Hernandes (2012, p. 152) “os espaços sagrados são lugares em que as pessoas encontram-se consigo mesmo (Imanente), com seu próximo e com o Transcendente.” Por elucidar as práticas ritualísticas e ser carregados de conhecimentos elementares que permeiam outros conteúdos da área de Ensino Religioso, como espiritualidades, os símbolos religiosos e os textos sagrados, tornam-se importante ferramenta para o desenvolvimento de ações educativas.

Esse processo interpretativo, carregado de significações para a exploração do sentido humano, transforma o espaço sagrado em um instrumento para a compreensão do fenômeno religioso como um todo. “A consciência teórica, prática e estética, o mundo da linguagem e do conhecimento, da arte, do direito e o da moral, as formas fundamentais da comunidade e do Estado, todas elas se encontram originariamente ligadas à consciência mítico-religiosa" (CASSIRER, 2000, p.42)

O diferencial do espaço sagrado é que apresenta uma dimensão material do ambiente, representada pelo paisagem concreta, bem como possibilita uma dimensão imaterial, representada pelos sentimentos produzidos na captação do espaço vivenciado, com suas diversas formas, cores, aromas, texturas e recriações ao longo dos tempos. "O homem não vive somente numa paisagem 'material', mas sim que de maneira consciente ou inconsciente, ele inventa universos imaginários, compostos de fatos de representação e de sonhos". (BARROS, 2002, p.6). 


\section{O Componente Curricular Ensino Religioso}

Ao longo dos tempos, muitas civilizações foram influenciadas pelas suas religiões predominantes, no que diz respeito às regras e comportamentos para o viver em sociedade que deveriam ser guiadas pelos valores espirituais vigentes na época. Com o passar do tempo, a moral e os valores pessoais e sociais continuaram sendo influenciados pelas novas religiões e a presença do ensino religioso na educação passa a ser necessária não somente para a alfabetização e para a formação cultural do indivíduo, mas também para a compreensão de outras áreas do conhecimento. Embora em determinados períodos houvesse uma resistência para a utilização de conteúdo religioso em território escolar, o ensino religioso sempre foi pilar para a construção da educação, seja ela orientada pelo Estado ou pelas Instituições religiosas em si. Um grande passo para o desenvolvimento do ensino religioso foi com a Declaração Universal dos Direitos Humanos, em 1948, que entre vários itens, aponta sobre

O direito à liberdade religiosa (XVIII) e a obrigatoriedade da instrução (XXVI), aspectos que favorecem a discussão sobre o Ensino Religioso como um componente no currículo em vista da formação de uma geração aberta ao diálogo e a novas relações socioculturais. (JUNQUEIRA, 2011, p. 36)

No Brasil, entre os períodos Colonial e Imperial, a educação era ministrada e controlada pelos jesuítas, marcadamente humanística devido às suas influências Renascentistas e voltada principalmente para a evangelização. Com a expulsão dos Jesuítas, por volta do século XVIII, o Estado passa a assumir a responsabilidade da educação, que passa a tornar-se mais racional e elitista, por influência do Iluminismo. Nessa fase, o ensino religioso, monitorado pela Inquisição, permanece para índios, escravos e o povo em geral, uma vez que somente a elite obtém educação das escolas da Coroa Portuguesa. Embora o sistema educacional sofra uma ampliação com a criação dos cursos superiores e a criação de bibliotecas e escolas especializadas, somente a elite usufruiu dessas mudanças, sendo que para as classes populares não houve significativo avanço. 
O ensino religioso nesse período não entra em conflito com o projeto político e permanece mais privativo por meio das Confrarias Religiosas que "ajudam a eliminar o hiato existente entre os da cultura européia e os da cultura africana, processando-se a efetivação do sincretismo religioso" (JUNQUEIRA, 2011, p. 38). Inclusive é no período Imperial que surge os primeiros questionamentos a respeito da diversidade religiosa, sendo Rui Barbosa o defensor de um ensino livre de imposição de uma determinada crença em particular.

Com o advento da República, o ensino, marcadamente influenciado pelo movimento Positivista, defende uma escola leiga, pública, gratuita e obrigatória rejeitando o ensino católico que tenderia a uma educação mais elitista. De acordo com Junqueira (2011, p. 38) a própria Constituição de 1934

Admite o Ensino Religioso, mas de caráter facultativo, ministrado de acordo com os princípios da confissão religiosa do aluno, sendo manifestada pelos pais ou responsáveis, constituindo matéria do currículo nas escolas públicas. Surgem grandes debates, retornando a questão da liberdade religiosa, a pressão da Igreja e tantos outros interesses.

Neste período, o Ensino Religioso sofre uma crise por sua perda de identidade pelo ensino catequético, pois uma vez que a escola torna-se autônoma, regida por seus próprios princípios e normas, marcadas por manifestações de pluralismo religioso, não há mais razão para haver um currículo responsável por doutrinar, que não atinja uma visão de mundo e do ser humano mais ampla. Assim, o catecismo perde sua força para dar lugar a novas possibilidades para o Ensino Religioso.

Sustentada pela Constituição da República Federativa do Brasil (1988), que no parágrafo primeiro do artigo 210 define que "O ensino religioso, de matrícula facultativa, constituirá disciplina dos horários normais das escolas públicas de ensino fundamental", a construção da Lei de Diretrizes e Bases define que o Ensino Religioso é base fundamental para a formação do ser humano, individual e socialmente e deve ser oferecida pelo Estado garantindo que será livre de proselitismos ou qualquer tipo de doutrinamento, ou seja, dará acesso a compreensão do fenômeno religioso e suas manifestações nas mais variadas religiões existentes, buscando sempre demonstrar a diversidade cultural 
brasileira e transformando o Ensino Religioso em um espaço para a reflexão e para o diálogo intercultural sem discriminações, conforme a Lei 9.475/97, que caracteriza o ensino religioso com a seguinte redação:

Art. 33. O ensino religioso, de matrícula facultativa, é parte integrante da formação básica do cidadão e constitui disciplina dos horários normais das escolas públicas de ensino fundamental, assegurado o respeito à diversidade cultural religiosa do Brasil, vedadas quaisquer formas de proselitismo. $\S 1^{\circ}$ Os sistemas de ensino regulamentarão os procedimentos para a definição dos conteúdos de ensino religioso e estabelecerão as normas para a habilitação e admissão dos professores.

$\S 2^{\circ}$ Os sistemas de ensino ouvirão entidade civil, constituída pelas diferentes denominações religiosas, para a definição dos conteúdos do ensino religioso. (BRASIL, 1997)

De acordo com a revisão deste artigo da Lei de Diretrizes e Base da Educação nacional caberá aos sistemas de ensino a regulamentação dos procedimentos para a definição dos conteúdos trabalhados na disciplina de ensino religioso.

\section{Experiências do uso do espaço sagrado e da arte sacra realizadas pela Secretaria Municipal de Educação de Curitiba}

No Estado do Paraná, os profissionais responsáveis pela disciplina na rede pública estadual do Paraná, com demais entidades que se preocupam com o Ensino Religioso, repensaram as fundamentações teóricas, os conteúdos a serem desenvolvidos em sala de aula, a metodologia de ensino, e elaboraram as Diretrizes Curriculares do Ensino Religioso nas Escolas Públicas do Sistema Estadual de Ensino do Paraná, visando desconstruir a idéia de 'aula de religião' para atingir um ensino mais democrático, voltado a diversidade cultural e religiosa do ser humano, definindo assim, como principal objeto de estudo, o Sagrado enquanto cerne da experiência religiosa, possibilitando ao aluno compreender a amplitude da própria cultura na qual se insere, assim "a educação religiosa visa formar pessoas críticas, participativas, fraternas, libertas (abertas ao transcendente), conscientes de serem parte de um todo" (PARANÁ, 2003, p. 195). 
Portanto, segundo o Currículo Básico para a Escola Pública do Estado do Paraná, a Educação Religiosa tem por finalidades:

- Estimular educandos e educadores a buscarem repostas às questões vitais, para que possam encontrar o sentido profundo e radical da existência; - Favorecer o desenvolvimento de uma integração, uma harmonia do ser humano consigo mesmo, com os outros, com o mundo e com Deus; - O desenvolvimento e a formação da pessoa humana no seu todo: intuitivo, consciente, crítico, comunitário, participativo, comprometido com a realidade social, política e econômica, ou seja, com a vida, como agente da história e construtor de uma sociedade mais justa, fraterna e solidária; Incentivar a vivência de valores que favoreçam as relações interpessoais mais humanas e fraternas;

- Cultivar a esperança de um mundo melhor que se inicia aqui e agora através da transformações das relações e das ações humanas, ainda que este seja um processo lento.

- Ajudar a Pessoa Humana a encontrar-se consigo mesma, comprometer-se com a sociedade e a conscientizar-se de ser parte de um TODO;

- Ajudar as pessoas a interpretarem em profundidade as suas vivências (experiências). ( PARANÁ, 2003, p. 198, 190).

Nota-se que dentro dos conteúdos da disciplina, está o estudo dos lugares sagrados, espaços estes que reúnem aspectos físicos que orientam a paisagem religiosa. Dentro do estudo dos espaços sagrados, insere-se o estudo do meio através do turismo educacional, ferramenta que possibilita ao aluno melhor compreensão do assunto, uma vez que o ensino é realizado no próprio espaço sagrado.

É através da vivência, dos estudos, dos contatos sociais, da participação no meio em que se vive, que o Ser Humano se insere na História. A Educação Religiosa, integrada na vida dos educandos, fará com que se percebam como partes integrantes de uma história que se desenvolve e na qual agem. (PARANÁ, 2003, p. 191).

O Currículo Básico para a Escola Pública do Estado do Paraná insere, dentro dos procedimentos pedagógicos, as visitas como uma das modalidades para a construção do saber no conteúdo dos espaços sagrados, uma vez que, além de possibilitar o acesso ao conhecimento, favorece uma maior sociabilização, reflexões e debates por parte dos alunos. "O resultado pedagógico desse contato não é mensurável em 
avaliações convencionais, apenas o tempo e a transformação do aluno em cidadão poderão demonstrar os reais valores adquiridos por todos. (ANDRIOLO; FAUSTINO, 2001, p.174).

O docente de Ensino Religioso precisa superar os antigos modelos educacionais e assumir a responsabilidade de promover a reflexão sobre a realidade. É distanciar-se das amarras da própria fé, é reconhecer a necessidade da pesquisa constante, é conceber-se como estudioso das manifestações do fenômeno religioso presente na sociedade e ser mediador desse conhecimento que compõe o currículo e as experiências pessoais de seus estudantes. (Hernandes, 2012, p. 15)

Conforme mencionado anteriormente em Jaluska; Junqueira (2013, 14-16) os professores que ministram as aulas do Ensino Religioso na Rede Municipal de Educação de Curitiba organizam sua ação docente a partir dos seguintes documentos: Diretrizes Curriculares para a Educação Municipal de Curitiba; Caderno Pedagógico de Critérios de Avaliação da Aprendizagem Escolar; e Caderno Pedagógico de Ensino Religioso.

Para aprofundar o conhecimento desses profissionais, a Secretaria Municipal da Educação disponibiliza, em parceria com a equipe pedagógica da Associação Inter-Religiosa de Educação (ASSINTEC), cursos de formação continuada voltados aos conteúdos do Ensino Religioso.

Para compreender o movimento desta disciplina no contexto Curitibano é fundamental retomar a historia, pois antes da década de 1970, o Ensino Religioso se fazia presente nas escolas a partir de esforços de voluntários que se dispunham a dar as denominadas aulas de religião nas escolas da rede pública. Não havia legislação neste sentido e não havia uma fundamentação no sentido de organizar um trabalho de modo sistemático.

Em 1973 teve um marco importante para a educação religiosa com o movimento ecumênico florescente, composto por um grupo de líderes de diversas denominações religiosas de Curitiba, juntamente com professores de rede pública de ensino, que tiveram a idéia de organizar uma associação que promovesse a implantação da educação religiosa organizada e de maneira sistemática e ecumênica. 
Surgiu assim a Associação Interconfessional de Educação (ASSINTEC), que caminha junto com a Secretaria Municipal de Educação (SME). A ASSINTEC é uma entidade civil, constituída de forma legal por diferentes representações das tradições religiosas, cuja finalidade é a orientação e a organização do Ensino Religioso dentro da proposta curricular das escolas públicas. Com a Lei de Diretrizes e Bases da Educação Nacional de 1996, sob novas bases, a ASSINTEC passou a trabalhar com o conhecimento religioso historicamente acumulado e vivido no contexto das Tradições Religiosas, Místicas e Filosóficas.

Em março de 2005, foi aprovado o novo estatuto da ASSINTEC, em que consta, entre outros aspectos, a acolhida de diferentes tradições religiosas, filosóficas e espiritualistas, além de entidades chamadas associadas. A ASSINTEC é representada no seu interior pelas seguintes tradições religiosas: Budismo Tibetano; Centro Ramakrishna Vedanta de Curitiba; Fé Bahá' Í; Federação Espírita do Paraná; Judaísmo; Islamismo; Iskon de Curitiba (Mandir-Sociedade Internacional) para a Consciência de Krishna; Igreja Católica Apostólica Romana; Igreja Ecumênica da Religião de Deus - LBV (Legião da Boa Vontade); Igreja Evangélica de Confissão Luterana no Brasil (Sínodo Paranapanema e Sínodo Rio Paraná); Igreja Menonita; Igreja Messiânica Mundial do Brasil; Igreja Ortodoxa Ucraniana; Igreja Presbiteriana do Brasil; Religiões Afro-Brasileiras: Candomblé e Umbanda; Seicho-No-Ie do Brasil (Membros Fraternos); URI (Iniciativa das Religiões Unidas); Brahma Kumaris.

Visando conhecer e analisar as diversas tradições religiosas, místicas e filosóficas e as prescrições de conduta que reforçam os valores em comum, a ASSINTEC, em conjunto com a SME, desenvolve planos anuais de formação continuada dos professores. Todo ano são oferecidos cursos de introdução ao Ensino Religioso, cursos de aprofundamento e encontros que requerem reflexão sobre arte e espiritualidade, bem como encontros para planejamento.

\subsection{Curso o fenômeno religioso nas tradições religiosas}

$\mathrm{O}$ curso previa quatro etapas e abordava os seguintes temas: $\mathrm{O}$ Fenômeno Religioso I - Tradições Religiosas da Matriz Judaico-Cristã (2006); O Fenômeno Religioso II - Tradições Religiosas de Matrizes 
Indígenas e Africanas (2007); O Fenômeno Religioso III -- Tradições Religiosas de Matriz Oriental (2008); O Fenômeno Religioso IV -Tradições Religiosas da Matriz Ocidental (2009).

Esses cursos proporcionam encontro entre professores e representantes religiosos das diversas tradições estudadas. Desse modo, favorece o conhecimento efetivo sobre religiões, tirando, ao mesmo tempo, dúvidas e facilitando a superação de preconceitos advindos de informações incorretas sobre determinadas religiões.

\subsection{Cadernos de Ensino Religioso}

Com referência ao desenvolvimento em seu trabalho pedagógico, de maneira especial o Ensino Religioso, os professores necessitam de modo constante de instrumentos de apoio que lhes permitam uma fundamentação segura. Visando dar apoio aos professores das escolas municipais, dois cadernos de Ensino Religioso, nos anos 2004 e 2003, foram elaborados. O Caderno $1 \mathrm{diz}$ respeito aos aspectos legais a que a área esta ligado. O Caderno 2 é uma complementação do anterior, trazendo exemplos de planejamentos de aulas para os Ciclos I e II. No ano de 2006, foram produzidos cadernos pedagógicos para os professores dos Ciclos I e II (do $1^{\circ}$ ao $5^{\circ}$ ano do Ensino Fundamental).

Em 2007, os professores regentes receberam um exemplar dos Cadernos Pedagógicos, cuja produção abrangia: Geografia, Ensino Religioso, História, Matemática e Alfabetização. Também os professores de Educação Física receberam cadernos específicos à sua área. Dos encontros, foram feitas avaliações em que professores e pedagogos registraram e ressaltaram a importância que foi dada aos esclarecimentos quanto ao objeto de estudo, aos conteúdos e à metodologia que o Ensino Religioso se propôs. Foi revelada a necessidade de ampliação da discussão dessa área. Também foi significativa a importância de se conhecer, valorizar e trabalhar com as diferenças individuais e culturais no ambiente escolar e de modo especial com as diferenças religiosas. A produção de material é contínua, haja vista que novas exigências e mudanças se operam. Parte dos materiais é confeccionada pelos próprios, usando uma metodologia própria, dentro do âmbito de sua compreensão e possibilidades, procurando desenvolver as aulas, partindo dos eixos temáticos do currículo, em 2010 o tema foi Textos Sagrados, em 2011, 
Respostas Norteadoras para o Sentido da Vida Além Morte e, em 2012, Espaços Sagrados (JALUSKA; JUNQUEIRA, 2013, p. 16-17).

\subsection{Curso Formação em Ação - Visita Técnica em Lugares Sagrados}

A idéia de estudar os Espaços Sagrados surgiu da necessidade relatada pelos próprios professores em conhecer as tradições religiosas para melhor fundamentar-se e, assim, oferecer uma dimensão mais clara da pluralidade religiosa na escola, buscando superar qualquer forma de preconceito. Nesse sentido, acompanhando o desenvolvimento do último caderno, Espaços Sagrados, foi desenvolvido o curso "Formação em Ação - Visita Técnica em Lugares Sagrados", que abrangia palestras ministradas pelos responsáveis de diversas religiões membros da Assintec, seguido por visitas monitoradas dentro dos próprios espaços sagrados.

Visita mediada do tema Hinduísmo

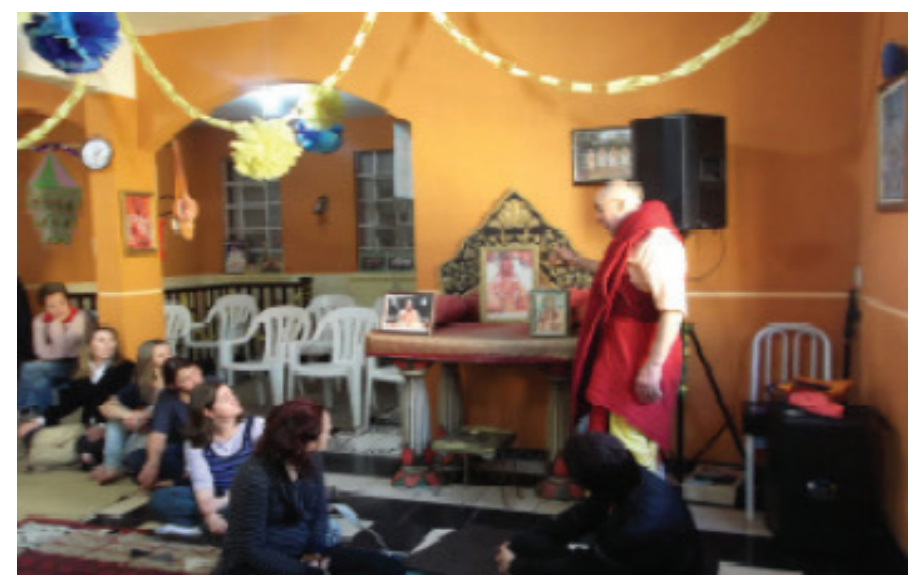

Fonte: Hernandes, 2012

O curso, segundo Hernandes (2012, p.152) foi planejado

com a intenção de proporcionar aos professores e pedagogos dos anos iniciais e finais do Ensino Fundamental o conhecimento sobre os Espaços Sagrados e suas representações e instrumentalizá-los na abordagem dos conteúdos de Ensino Religioso e possíveis visitas monitoradas com os estudantes, em diferentes espaços sagrados. (HERNANDES, 2012, p. 152) 
Para o desenvolvimento deste projeto foram selecionadas instituições religiosas que a partir da parceria da ASSINTEC participam deste processo pedagógico de compreensão das manifestações religiosas por meio de seus espaços religiosos.

\subsection{Trilha do Sagrado: Redescobrindo o Centro Histórico de Curitiba}

A Trilha do Sagrado, projeto mais recente, iniciado em 2017, foi desenvolvida pela Secretaria Municipal da Educação para apresentar a diversidade religiosa de Curitiba para os visitantes sem sair do centro da cidade. Durante o passeio, que tem duração aproximada de duas horas e feito a pé, os participantes conhecem a cultura, fé e a história das quatro matrizes religiosas, cristã, oriental, africana e indígena.

A trilha começa na Praça Tiradentes, onde os participantes conhecem os irokos (árvores dispostas em círculos e que são sagrados para as religiões de matriz africana), a escultura do índio Tindiquera e a Catedral de Curitiba, seguindo pelo Largo da Ordem, onde conhecem as Igrejas da Ordem, Presbiteriana, Independente e do Rosário, pela sede do instituto Hare Krishna, pela igreja Luterana e pela mesquita Iman Ali Ibn Abi Talib. Em cada local, são apresentados os aspectos religiosos, a arquitetura, a arte, a história, origem, entre outras informações e também é tirado as dúvidas dos participantes.

Visita mediada na Trilha do Sagrado: Catedral de Curitiba

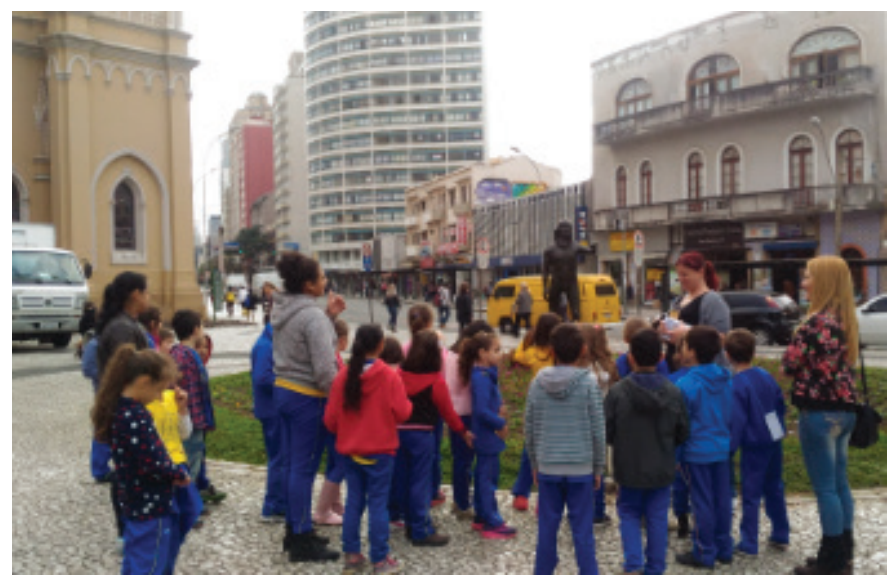

Fonte: JALUSKA, 2017 
Segundo Willms (2017), professora da rede municipal de Curitiba, integrante da equipe de currículo da Secretaria Municipal da Educação e responsável pela atividade, a ideia da criação da Trilha surgiu quando foi pedido um encaminhamento de uma atividade de cada disciplina para trabalhar o aniversário de Curitiba. Então, olhando para o currículo do primeiro semestre do ensino religioso que aborda os lugares sagrados e organizações religiosas, foi desenvolvido para as crianças pequenas um jogo de memória com alguns lugares sagrados das quatro matrizes religiosas e para os mais velhos foi distribuído um mapa do site da prefeitura com os lugares sagrados do Largo da Ordem marcados, onde a criança percorria esse mapa e, cada vez que encontrava um lugar sagrado, ganhava uma cartinha contendo alguma informação dele.

Durante a realização da atividade muitos professores ficaram curiosos com espaços que não conheciam na cidade e daí surgiu a primeira visita com esses professores. Como a Prefeitura de Curitiba acompanhou a visita e postou nas redes sociais, muitas pessoas se interessaram pelo assunto e manifestaram interesse em participar. A partir daí, a visita que era foi realizada apenas uma vez, tornou-se permanente.

O principal objetivo da atividade é mostrar para as pessoas que Curitiba possui uma grande diversidade religiosa o que causa muita surpresa nos participantes, por exemplo, quando é contado que a cidade tem o segundo maior terreiro de Umbanda no Brasil. Segundo Willms (2017), existe a possibilidade de criar dentro do Setor de Cultura da Educação um núcleo de Cultura Religiosa o que auxiliaria em muito na divulgação da Trilha, "porque a gente faz a divulgação no Ensino Religioso, mas atinge um público muito pequeno, se a gente consegue essa parceria da parte da Cultura a gente atinge toda a rede e são dezessete mil professores enquanto que, de ensino religioso, são apenas trezentos".

Alguns aspectos significativos da Trilha, como conta Willms (2017), é que durante o trajeto, é possível perceber como a educação em história e geografia dos participantes é falha, pois quem tem mais de vinte anos não tem tanto conhecimento de outras etnias que não a européia em Curitiba. Outra questão apontada por Willms (2017) é que a Trilha valoriza o trabalho do professor de Ensino Religioso, pois além de mudar a visão da própria disciplina, o roteiro motiva os professores 
em seu trabalho diário, "porque professor de Ensino Religioso é muito marginalizado dentro da própria escola, desde a escolha da função até o trabalho que ele desenvolve, ele sofre muito preconceito dentro da própria escola". Com a divulgação da Trilha, no site da prefeitura, no facebook, com as entrevistas dadas em rádios da cidade, torna visível a importância do trabalho do professor de Ensino Religioso para a sociedade.

Com relação à compreensão do cenário religioso por parte dos participantes, Willms (2017) destaca exemplos como a lavação das escadarias da Igreja do Rosário, evento que fica muito fechado no grupo religioso e com a visita é possível falar desses eventos para as pessoas que não fazem parte daquela organização ampliando assim o conhecimento.

Visita mediada na Trilha do Sagrado: irokos

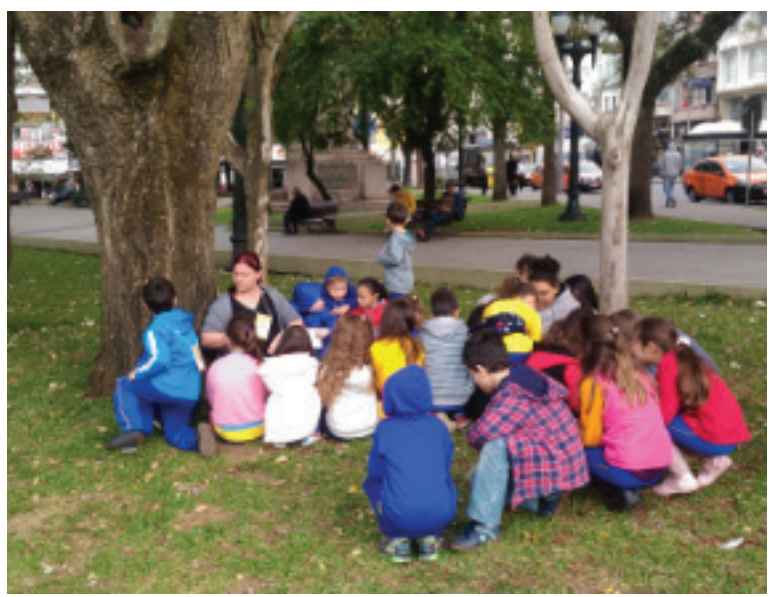

Fonte: JALUSKA, 2017

Outro exemplo são os irokos, que, quando explicado a história do porquê aquelas árvores são sagradas, as pessoas conseguem entender melhor a manifestação religiosa de matriz africana e quando estiverem andando pela cidade e encontrarem uma oferenda embaixo, estiver com flores, a visão já vai ser bem diferente relacionada aquele lugar, a questão do respeito de entender que aquela árvore naquele momento é um lugar sagrado para uma determinada pessoa e deve ser respeitado. 


\section{Considerações finais}

A educação não pode dissociar a experiência de sentido humana presente na história das experiências de sentido religiosas, pois para compreender a identidade do ser humano em sua totalidade faz-se necessário compreender suas articulações mítico-religiosas dentro da diversidade cultural, sendo assim, a arte sacra dos espaços sagrados tornam-se essenciais na medida em que fornecem a educação, de maneira privilegiada, as diferentes compreensões que o ser humano tem de si mesmo, do mundo material e espiritual.

Esse processo interpretativo, carregado de significações para a exploração do sentido humano, transforma os espaços sagrados em instrumentos para a compreensão do fenômeno religioso como um todo, pois os espaços existentes fora da sala de aula também podem ser aproveitados para realizar atividades educativas. Muitas vezes, a aprendizagem de determinados conteúdos requer a exploração de espaços na comunidade, para que os conteúdos possam ser melhor assimilados favorecendo um aprendizado mais amplo e dinâmico.

Sendo Curitiba uma cidade composta de diferentes manifestações étnico-religiosas, muitos espaços ficam ocultos na paisagem urbana e, com a realização de práticas de educação patrimonial nesses espaços, é possível expandir o conhecimento, ou seja, divulgar o histórico, arquitetura, história dos respectivos espaços que até então passava despercebido aos olhos dos visitantes.

A compreensão do cenário religioso por parte dos visitantes é um dos principais aspectos que torna a ação educativa de extrema importância para a sociedade, pois permite que os visitantes compreendam melhor como a cidade foi formada, seu desenvolvimento, a compreensão de suas próprias raízes religiosas bem como permite compreender aspectos de outras religiões que também fazem parte da história e do cotidiano da cidade.

É possível perceber que o que mais chamam a atenção tanto professores quanto alunos e demais visitantes são os elementos culturais de outras religiões que são distantes de seu cotidiano e essa curiosidade acaba facilitando a difusão do conhecimento da diversidade religiosa existente na cidade e contribuindo para a construção de um ensino 
religioso mais inclusivo, democrático e plural, ou seja, voltado para a diversidade religiosa.

Nesse tipo de atividade, o aluno passa a conhecer melhor o local onde vive, reconstruindo a historicidade do lugar e percebendo seu papel de protagonista, possibilitando criar um sentimento de pertença a comunidade em questão. Além disso, conhecer o diversificado patrimônio religioso de sua cidade permite ao indivíduo respeitar as diferentes manifestações culturais e a melhor compreendê-las, desenvolvendo sua própria identidade com o local do qual faz parte e facilitando o preparo do professor para trabalhar o componente curricular de maneira enriquecedora.

Nesse sentido, apresentar as diferentes ações da Secretaria Municipal de Educação de Curitiba e dseu impacto para a construção de um componente curricular ainda em formação torna-se parte da estratégia para se pensar novas políticas pedagógicas que possibilitem maior diálogo entre os atores, coloquem a educação em evidência e provoquem mudanças significativas no modo de ensinar nas escolas contemporâneas. Assim, este estudo não pretende esgotar o tema proposto, mas sim oferecer pontos de vista importantes para a realização de novos estudos que continuem desenvolvendo esse importante tema educativo.

\section{Referências}

ANDRIOLO, Arley; FAUSTINO, Evandro. Educação, turismo e cultura. A experiência de estudantes paulistas em uruçanga. IN: RODRIGUES, Adyr. Turismo e Geografia: reflexões teóricas e enfoques regionais. 3. ed São Paulo: Hucitec, 2001.

BARROS, Nilson Cortez Crocia de. Manual de geografia do turismo: meio ambiente, cultura e paisagens. Recife UFPE, 2002.

BRASIL. LDBEN n. 9.394/96. Lei de Diretrizes e Bases da Educação Nacional. Brasília, 1996.

CALVANI, Carlos. Teologia da Arte. Espiritualidade, Igreja e Cultura a partir de Paul Tillich. Fonte Editorial, 2010.

CASSIRER, Ernst. Linguagem e mito. São Paulo: Perspectiva, 2000 
FERNANDES, Márcio Luiz. A perspectiva invertida: a estética teológica em Pavel Florenskij, In PERETTI, C. Filosofia do gênero em face da teologia. Champagnat, Curitiba 2011, pp. 311-321.

GIL FILHO, Sylvio Fausto. Espaço Sagrado: Estudos em Geografia da Religião. Curitiba: Ibpex, 2008. 119 p.

HERNANDES, Elisabeth Cristina Carassai. Espaços sagrados: Formação continuada dos professores da rede estadual do Paraná e municipal de ensino de Curitiba. Caderno Est. Pes. Tur. Curitiba, v.1, p. 144-155, jan./dez. 2012.

JALUSKA, Taciane Terezinha; JUNQUEIRA, Sérgio Rogério Azevedo. Projeto Espaço Sagrado: uma proposta de turismo educacional e uma estratégia para conhecer e educar. Caderno de Estudos e Pesquisas do Turismo. Curitiba: v. 2, p. 12-25, jan/dez 2013.

JUNQUEIRA, Sérgio Rogério Azevedo. A presença do ensino religioso no contexto da educação. In: JUNQUEIRA, Sérgio Rogério Azevedo; WAGNER, Raul. O Ensino Religioso no Brasil. Editora Champagnat: Curitiba, 2011.

KANDISNKY, Wassily. Do espiritual na arte e na pintura em particular. São Paulo: Martins Fontes, 1996

PARANÁ, Secretaria do Estado da Educação. Currículo Básico para a escola pública do Estado do Paraná. Curitiba: 2003

PASTRO, Cláudio; TAVARES, André. Iconografia como expressão da fé. In: MARIANI, Ceci Baptista; VILHENA, Maria Angela. (org.) Teologia e Arte: expressões de transcendência, caminhos de renovação. São Paulo: Paulinas 2001. Coleção teologia na universidade.

SÁEZ, F.J. ¿Qué es una obra de arte? Memoria y realismo simbólico en Pavel Florenskij.iin Numenor X/22 (2009), pp. 45-60

SILVA, Alex Sandro da; GIL FILHO, Sylvio Fausto. Geografia da Religião a partir das Formas Simbólicas de Ernst Cassirer: um estudo da Igreja Internacional da Graça de Deus no Brasil. Revista de Estudos da Religião: junho, 2009, p.73-91

TILLICH, Paul. Teologia Sistemática: três volumes em um. São Paulo: Paulinas, 1967. $725 \mathrm{p}$.

WILLMS, Karin. Na Trilha do Sagrado. Entrevista concedida a Taciane Jaluska na Secretaria Municipal de Educação de Curitiba. Junho/2017 